\title{
İşyerinde Etik Algısı Cinsiyete ve Kuşaklara Göre Değişir mi? Türkiye'deki Çalışanlar Üzerine Ampirik Bir Çalışma
}

\author{
Müge Leyla Yıldız1 이, Selay Giray Yakut² 다
}

Öz

Çalışanların etik dışı davranışları örgütte yaratth̆ı̆ ciddi olumsuz sonuçlar nedeniyle incelenmesi gereken önemli bir konudur. Ancak çalışanların davranışlarına yansıyan etik algılarını anlamak ve yönetmek oldukça karmaşık bir konudur. Etik algısını anlama çabasının geniş bağlamda ele almasının gerekliliği göz önüne alınarak bu çalışmanın amacı işyerinde etik algısının cinsiyete ve kuşaklara göre farklııklarının tespit edilmesidir. Türkiye'de $Y$ kuşağından $460, X$ kuşağından 256 ve bebek patlaması kuşağından da 112 olarak toplamda 828 çalışan araştırmanın örneklemini oluşturmaktadır. Araştrma sonucunda işyerinde etik dışı davranışa gösterilen tolerans cinsiyete göre ve kısmen kuşaklara göre farklılaştı̆ı görülmektedir. Ayrıca Türkiye'deki Y kuşağının göreceli olarak etik dışı davranmaya diğer kuşaklardan daha meyilli olduğu görülmüştür. Araştırma sonuçları, sınırlııkları açıklanmış ve uygulamaya yönelik öneriler sunulmuştur.

Anahtar Kelimeler

Etik algısı • Kuşak farklılıkları • Cinsiyet • Y kuşağı •X kuşağı • Bebek patlaması

\section{Are Gender and Generational Differences in Ethical Perceptions Real? An Empirical Study on Workplace in Turkey}

\begin{abstract}
Managing ethical perceptions is a complicated and important problem because unethical behavior can cause many negative outcomes for business organizations. The purpose of the study is to determine the gender and generational differences in ethical perceptions in the workplace. The sample of the study is 828 workers (460 of Gen Y, 256 of Gen X and 112 of baby boomers) In Turkey. The findings suggest that women are more ethical than men. There is also evidence to suggest that generational differences are an important factor in understanding the differences of ethical perceptions of workers in the workplace. Moreover, Generation $Y$ in Turkey tend to be more tolerant of unethical behavior than Generation $X$ in the workplace. The results, limitations, and implications of the research is presented for managers.
\end{abstract}

\section{Keywords}

Ethical perception • Generational differences $\bullet$ Gender $\bullet$ Millennial $\bullet$ Generation $\mathrm{Y} \bullet$ Generation X $\bullet$ Baby Boomers

\footnotetext{
1 Sorumlu Yazar: Müge Leyla Yıldız (Doç. Dr.), Marmara Üniversitesi, İşletme Fakültesi, İşletme Bölümü, İstanbul, Türkiye.

E-posta: mlyildiz@marmara.edu.tr ORCID: 0000-0001-7618-4529

2 Selay Giray Yakut (Doç. Dr.), Marmara Üniversitesi, İktisat Fakültesi, Ekonometri Bölümü, İstanbul, Türkiye.

E-posta: selaygiray@marmara.edu.tr ORCID: 0000-0003-4002-7956

Atıf: Yildiz, M. L., \& Giray Yakut, S. (2019). İşyerinde etik algısı cinsiyete ve kuşaklara göre değişir mi? Türkiye'deki çalışanlar üzerine ampirik bir çalışma. Istanbul Business Research, 48(2), 197-217. http://doi.org/10.26650/ibr.2019.48.0027
} 


\section{Extended Summary}

The purpose of this study is to examine the relative differences between gender and generations which are two important factors in the workplace. The study is based on a high representative sample in the workforce in Turkey. Additionally, in this study, the differences in variables, such as being a manager and having job security, which can change the perception of ethics, were discussed.

In general, studies conducted with student sample showed that male students were more tolerant of unethical academic behavior than women (Lane, 1995; Luthar et al., 1997; Whitley, Nelson and Jones, 1999; Peterson, Rhoads and Vaught, 2001; Glover et al., 2002; Beu et al., 2003; Roxas and Stoneback, 2004; Boyd, 2009; Curtis et al., 2012).) Although there are also some contrasting results (Jaffee and Hyde, 2000), the research hypothesis created to assess gender differences reagrding ethical perception in Turkey is as follows:H1: Ethical perception in the workplace differs according to gender.

According to the literature (Glover et al., 2002; Franke et al., 1997; Harris, 1990), the research hypothesis to measure the effect of experience in the workplace on an increasing gender gap is as follows:

H2a: Gender differences in ethical perception diminish as the employee's experience in the sector increases.

H2b: Gender differences in ethical perception diminish as the employee's experience in the company increases.

There is a relative comparison in the gender comparison. Whether the employees have managerial/executive position or not and different sectors in which they work affect this comparison. The research hypotheses on this subject are as follows:

H3a: Gender differences in ethical perception vary by sector.

H3b: Gender differences in ethical perception vary depending on whether or not they are managers.

Those who have more experience and job security have higher ethical perception (Ergenli and Arikan, 2002). In this case, the research hypothesis is as follows:

H3c: Gender differences in ethical perception vary according to employee's job security status (public / private).

According to Mitchell et al. (1992), young employees have more ethical awareness than older ones. Although the results are quite different (Dalton and Ortegren, 2011, Loe et al., 2000; O'Fallon and Butterfield, 2005), the research hypothesis developed regarding age is as follows: 


\section{H4: There is a negative correlation between age and tolerance to ethical behavior.}

In addition, the generation theory tends to better explain the differences in ethical perception and reasoning according to age. In this context, the research hypothesis is as follows:

H5: Generation X (Gen X), Generation Y (Gen Y) and the baby boomer generation (baby boomers) differ in terms of ethical behavior perception.

Moral decision making tends to be higher in women or in ethical dilemmas women tend to behave more ethically (Weber and Urick, 2017; Parry and Urwin, 2011; Herrington and Weaven, 2008; Terjersen et al., 2007) Accordingly, the research hypothesis developed to measure the ethical perception of women and men of the same generation is as follows:

H6: Women in X, Y and the baby boomer generations tend to behave more ethically than men of the same generation.

\section{Methodology}

In order to measure ethical perception, the 10-question scale developed by Froelich and Kottke (1991) and Cole and Smith (1995) and adapted by Cagle and Baucus (2006) was used. "The employee may need to lie to the customer to protect the business." is an example of scale questions. A 6-point Likert scale (from $1=$ Strongly Disagree to $6=$ Strongly Agree) has been used to evaluate the questionnaire $(\alpha=.866)$.

The birth dates suggested by Zemke, Raines and Filipczak (2013) and updated and adapted by Costanza et al. (2012), Yildiz (2016), Saruhan and Yildiz (2018) were used to determine the age ranges of the generations. According to age ratio in Turkey, 460 employees from generation Y (55.6\%), 256 employees from generation X (30.9\%) and 112 employees from baby boomer generation (13.5\%) are determined by proportional sampling method.

\section{Conclusion and Discussion}

According to research results, it has been determined that females have higher ethical perception than males and female managers have more than male managers in the sample in Turkey (similar to Atakan, Burnaz and Topcu, 2008; Ekin and Tezolmez, 1999; Ergeneli and Arikan, 2002). However; results show that, in contrast to the literature, generation $\mathrm{Y}$ in Turkey tend to behave more unethically than generation $\mathrm{X}$ and baby boomers. While ethical leadership, ethical values and codes are on the agenda of the whole world, studies in different samples in the literature show that generation $\mathrm{Y}$ ethical codes and expectations are high (Curtin et al., 2001) and that they are prone to high ethical codes of servant leadership and they will endeavor not to behave unethically (Vanmeter et al., 2013). The results of generation $Y$ reveal that they tend to be less ethical than previous generations in Turkey. In this context, 
it is an important indicator of how work has changed over the generations from society to society even in such a global and informed world.

Research results show that members of generation Y, defined as responsible leaders at a global level (Williams and Turnbull, 2015) and employees with servant leadership characteristics (Vanmeter et al, 2013) in the literature, in Turkey tend to behave unethically and accept these behaviors more than previous generations. The potential for unethical behavior of future corporate leaders in companies is an issue that needs attention (Hanna et al., 2013). Ethical training may be the first suggestion for organizations, but it will be one of the most effective methods of self-culturing in the Millennium which will create a role model for ethical issues to shape ethical reasoning.

The main contribution of this research is that it investigates the level of tolerance of unethical behavior in Turkey with a large sample composed of 828 employees, not students. As seen in Weber and Urick's $(2017,2018)$ current studies, while generation Y, composed of American students, tend to behave more ethically, the ethical perception of generation $\mathrm{Y}$ in Turkey shows differences. 


\section{İşyerinde Etik Algısı Cinsiyete ve Kuşaklara Göre Değişir mi? Türkiye'deki Çalışanlar Üzerine Ampirik Bir Çalışma}

Son 10 yıldır işletme başarısızlıklarının etik dışı davranışlardan ve bu davranışların sonuçlarından kaynaklandığı dikkatleri çekmektedir. Enron, WorldCom, Xerox, Volkswagen, Roche gibi etik skandalları yakın zamanda tüm dünyada, ekonomide ve dolayısıyla işletmelerde etik konulara daha özen gösterilmesini sağlamıştır. Kar amaçsız sosyal girişimlerin popülerlik kazanması, işletmelerde etik kodların netleştirilerek uygulanılmaya çalışılması, etik liderlerin aranması gibi konular dikkatleri işletmelerde etik davranış algısının nasıl şekillenmekte olduğuna çevirmiştir. Miesing ve Prable (1985)'e göre etik, insanın doğruyu yanlıştan ayırmasını sağlayan benimsedikleri ahlaki prensipler ile ilgili çerçevedir. Etik ahlaki zemini ifade etmektedir. Ahlak ise bireyin muhakemelerinde kullanılan, standartlar ve prensiplerden oluşan değerler bütünüdür (O’Fallon ve Butterfield, 2005). Etik kodların varlığı, mutlaka uyulması gereken kuralları belirlemekte ve uyulmaması durumunda topluluktan atılma gibi sonuçlar yaratmaktadır (Bullock ve Panicker, 2003). Etik kodları oluşturan değerler, tutumlar1; tutumlar da davranışları şekillendirdiği için eğer çalışanların etik dışı davranışlara karşı toleranslıysa buna göre tutum ve davranış geliştireceği için algı düzeylerini anlamak önemlidir (Greenwood, 2013). Etik dışı davranışların yaratacağı olumsuz sonuçlar kadar bu davranışları kabul eden ya da bunlara tolerans gösteren etik dışı çalışma ikliminin oluşması, işletmelerin tüm paydaşları için ciddi sorun teşkil etmektedir.

İşletmelerde etik davranışları yönetmek kuşkusuz ki en önemli sosyal sorunlardan biridir. Çalışanların etik ya da etik dışı karar vermelerini etkileyen faktörleri derinlemesine anlama gerekliliği nedeniyle de karmaşık bir sorundur (Craft, 2018). Thomas ve diğerleri (2004) çalışanların tutarlı etik davranışlar sergilemesinin şansa ya da dış etmenlere bırakılamayacağını bu konuda yöneticilerin stratejik lider olarak etik bir iklim kurması gerekliliğini vurgulamaktadır. Böylece çalışanlar bilinçli ve tutarlı bir şekilde etik dışı davranışlardan kaçınacaklardır.

Etik algısı, göreceli olarak etik ikilemlerde olayın algılanmasını ve farkındalığını ifade etmektedir (Wittmer, 2000). Bazı çalışmalar etik durumlara ve etik/etik olmayan davranışlara farklı kültürlerde farklı hassasiyetlerin ve tepkilerin verildiğini göstermektedir (Loe ve diğerleri 2000; Hay ve diğerleri, 2001; Marta ve diğerleri, 2003). Etik görecelik (Ethical Relativism) bir davranışın iyi ya da kötü, doğru ya da yanlış olarak algılanmasının toplumdan topluma ve kültürden kültüre değiştiğini öne sürmektedir. Görecelilik ya da rölativizm bireylerin ahlaki karar verecekleri zaman evrensel ahlak kural ve normlarını görmezden gelme derecesidir (Vanmeter ve diğerleri, 2013). Kişisel ahlak genellikle toplumsal/ulusal ahlak kurallarına göre şekillenir. Bu durumda evrensel olarak yanlış olsa da bir toplulukta doğru olarak kabul edilebilen ahlaki davranışlar söz konusudur. Benzer şekilde bir işletmede etik dışı davranışların kabul görmesi, çalışanların etik algılarını da şekillendirmektedir. 
Etik algısını yönetmek günümüzde üç hatta belki dört kuşağın birlikte çalıştı̆̆ bir ortam haline gelen işletmelerde daha da zorlaşmıştır. Benzer coğrafyada benzer sosyal olayları deneyimlemiş benzer yaş grubunda olan bir grup insanı (Costanza ve Finkelstein, 2015) ve onların birbirine benzer özelliklerini algı, tutum ve davranışlarını açıklayan kuşak teorisine yönelik tartışmalar ve eleştiriler devam etmektedir. Ancak kuşak farklılıklarının çalışanın iş yapış tarzından, işe alma, eğitim ve geliştirme, kariyer gelişimi, ödül sistemi ve yönetim şekline kadar birçok uygulamayı şekillendirdiği görülmektedir.

Yöneticilerin işletmelerde kuşak farklılıklarını en iyi ne şekilde yöneteceklerine dair önerilere ihtiyacı vardır (Parry ve Urwin, 2011). Kuşakların amaçlarının, beklentilerinin, iş değerlerinin, yönetici/lider tercihlerinin, etik algılarının farklı olduğu yönünde varsayımlar ve çalışmalar mevcuttur. Yöneticiler, insan kaynağı uzmanları, araştırmacılar da iş hayatına giren yeni kuşakları nasıl yönetip yönlendireceklerini incelemeye başlamışlardır (Cennamo ve Gardner, 2008). Ancak bu önermeler az sayıda niceliksel bilimsel çalışma ile test edilmiştir.

Etik algısının cinsiyete ve kuşaklara göre farklılıklarını konu alan çalışmalar genelde Kuzey Amerika ve genişleyen bir şekilde de Asya-Pasifik bölgesini ele almaktadır. Etik algının şekillenmesinde kültür, farklı değerler ve farklılaştırılmış etik ikilemler yaratarak insanların algılarını şekillendirme konusunda oldukça etkilidir (Ho, 2010). Bu nedenle kültürel; etik, cinsiyet ve kuşak çalışmalarında örneklem son derece önemlidir. Geleceğin potansiyel yöneticileri, çalışanları ve girişimcileri olarak işletme öğrencileri üzerinde yapılan araştırmalar yanı sıra işletmelerdeki çalışanların işyerinde etik algısını ölçme konusunda da deneysel çalışmalara ihtiyaç duyulmaktadır. Bu konuda Türkiye'de çalışanlar örnekleminde yapılmış araştırmalar sınırlıdır.

Etik algısının cinsiyet ve kuşak farklılıklarını konu alan çoğu deneysel çalışma büyük örneklemlerle çalışmaktan ziyade gözleme odaklanmıştır. Ayrıca Türkiye örnekleminde yapılan çalışmalar genelde farklı uzlanım alanlarındaki öğrenciler ile yalnızca pazarlama ve satış, muhasebe, denetim ve akademisyenlik gibi mesleki etik algısı üzerinde gerçekleştirilmiştir. Etik algısı işletmenin tüm çalışanları için önemli sonuçlar yaratabilecek bir konudur. Bu bağlamda araştırmanın amacı Türkiye'deki çalş̧anlar üzerinde temsil gücü yüksek bir örneklemde işyerinde etik algısında iki önemli faktör olan cinsiyetin ve kuşakların göreceli farklılıklarını incelemektir. Ayrıca etik algısını değiştirebilecek yönetici olma durumu, iş güvencesine sahip olma gibi değişkenlere göre farklılıklar da ele alınmıştır.

$\mathrm{Bu}$ araştırma birçok yönden yazına katkı sağlayacaktır. Birincisi örneklemi temsil gücü yüksek bir araştırmadır. İkinci olarak cinsiyet farklılıklarını da ele alarak yerli ve yabancı yazına katkı sağlamayı amaçlamaktadır. Üçüncü olarak da etik tutumlar ve özelikle kuşakların iş ortamındaki algılarını kıyaslama ve karşılaştırma olanağı sağlamaktadır. 
Çalışma üç bölümden oluşmaktadır. Literatür taraması ve hipotezlerin geliştirilmesinin ardından araştırmanın yöntemi detaylı olarak açıklanacaktır. Son olarak bulgular ve hipotez testi sonuçları değerlendirilecek ve sonuçlar tartışılacaktır.

\section{Literatür Taraması ve Hipotezlerin Geliştirilmesi}

Etik kelimesi Eski Yunanca kökenli ethos'dan gelmektedir. Ahlak kelimesi ise töre, gelenek ve görenek anlamlarında gelen mos kökünden gelmektedir. Etik algısı, bireylerin kişisel ilişkilerinde ahlak ve toplum standartlarının uygulanmasını gerekli gördüğ̈̈ düzeyi ifade etmektedir (Pruden, 1971; Shaffer ve O'hara 1995). Bireylerin işyerindeki etik davranışları iş etiğinin konusudur. Araştırmaya konu olan işyerinde etik algısının cinsiyete ve kuşaklara göre farklılık gösterip göstermediğine dair literatür tartışması ve hipotezlerin gelişim süreci şu şekildedir:

\section{Etik Algısı ve Cinsiyet}

Kadınlar ve erkekler birbirlerinden psikolojik ve davranışsal olarak farklılaşırlar. Eagly (1987) tarafından ortaya atılan Sosyal Rol Teorisi (Social Role Theory), sosyal davranışlardaki cinsiyet benzerlikleri ve farklılıklarının toplumdaki sosyal roller olduğunu öne süren bir sosyal psikoloji teorisidir. Bireyler kendilerinden beklenen cinsiyete dair rollerin özelliklerine sahip olma eğilimdedirler (Eagly ve Wood, 2016). Teoriye göre, cinsiyete dair bu farklılıklarının nedeni de küçük yaşlarından beri gerçekleşen sosyalleşme sürecidir (Wagner ve diğerleri, 1993). Bu bağlamda da kadınların erkeklerden daha fazla etik karar verme eğilimde olması sosyalleşme sürecinde kendisinden beklenen roller ile ilgilidir. Başka deyişle kadınlar ve erkekler toplumda farklı roller üstlenerek sosyalleşirler. Toplumda belirlenen cinsiyet rolleri işletmelerdeki etik algısını da şekillendirmektedir.

Cinsiyetler arasındaki sosyal konulara bakış ve etik davranış/algı farklılıkları literatürde oldukça fazla araştırmaya konu olmuştur. Bazı araştırmalar kadınların erkeklere oranla daha az etik dışı davranışa yöneldiğini ifade etmektedir (Cole ve Smith, 1996; Luthar ve diğerleri, 1997). Erkekler arasında daha rekabetçi, saldırgan değerler yaygınken kadınlar arasında işbirliği, duygusal yakınlık ve eşitlik gibi değerler daha fazla görülmektedir. Bu değer farklılıkları da iş tutumlarının, davranışlarının ve etik algılarının da farklılaşmasına neden olmaktadır (Ergeneli ve Arıkan, 2002). Kadınlar ahlaki sorunları itina, merhamet ve empati sorunu olarak görürken; erkekler hak, adalet ve eşitlik sorunu olarak görmektedir (Gilligan, 1982).

Kohlberg $(1969,1984)$ çalışmalarını Cinsiyet Sosyalizasyon Yaklaşımı (Gender Socialization Approach) üzerine inşa etmiştir. Gilligan $(1982,1990)$ cinsiyetlerin ahlaki odağ üzerine de çalışmalar yapmıştır. Bireyler kendi cinsiyet rollerinin sosyalizasyon sürecinden etkilenmektedir (Roxas ve Stoneback, 2004). Bu durum da cinsiyetler arasinda etik kodlar, tutum ve davranışlarda farklılık yaratmaktadır. 
Genellikle Journal of Business Ethics dergisinin sayılarında görülen Ford ve Richardson (1994), Roxas ve Stoneback (2004), Weeks ve diğerleri (1999), Collins (2000), Lund (2008), Weed (2009) ve daha birçok yazar etik ile cinsiyet konusunu ele almıştır. Birçok çalışma kadınların erkeklerden daha fazla etik davranmaya eğilimli olduğunu belirtmiştir. Bazı örnek olaylarla kadın satış elemanlarının (Boyle, 2000) bazıları da kadın pazarlama elemanlarının (Lund, 2008) daha etik davrandığını tespit etmişlerdir.

Franke, Crown ve Spake (1997) 66 çalışma örneklemini dâhil ettikleri etik karar vermede cinsiyetin rolünü araştırdıkları meta analiz çalışmalarında işletme uygulamalarında kadınların etik standartlarının erkeklere oranla daha yüksek olduğunu tespit etmişlerdir. O’Fallon ve Butterfield (2005) yaptıkları meta analizinde cinsiyetler arasında farklılığın olduğu çalışmalarda kadınların erkeklerden daha etik davrandıkları sonucuna ulaşmıştır. Ayrıca etik dışı iş uygulamalarını erkeklerin kadınlardan daha fazla kabul etme eğilimde oldukları (Eagly, 2005) görülmektedir.

Genelde öğrenci örneklemiyle yapılan çalışmalarda da erkek öğrencilerin kadınlara oranla akademik etik dışı davranışlara daha toleranslı oldukları görülmektedir (Lane, 1995; Luthar ve diğerleri, 1997; Whitley, Nelson ve Jones, 1999; Peterson, Rhoads ve Vaught, 2001; Glover ve diğerleri, 2002; Beu ve diğerleri, 2003; Roxas ve Stoneback, 2004; Boyd, 2009; Curtis ve diğerleri, 2012). Jaffee ve Hyde (2000) 113 deneysel çalışmayı dâhil ettikleri meta analiz çalışmalarında ahlak odaklılığın cinsiyete göre farklılaşmadığını bulmuştur. Bazı çelişen sonuçlara rağmen çalışmalarda tespit edilen ilişkinin varlığı doğrultusunda Türkiye örnekleminde test etmek amacıyla araştırma hipotezi şu şekildedir:

\section{$H_{1}$ : İsyerindeki etik algısı cinsiyete göre farklılaşır.}

Harris (1990) 10 yıldan az iş tecrübesine sahip çalışanların daha kıdemli çalışanlara göre etik ikilemlerde daha toleranslı olduklarını, Glover ve diğerleri (2002) ise iş tecrübesi ile etik algısı arasında pozitif ilişki olduğunu ifade etmektedir. Franke, Crown ve Spake (1997) meta analiz çalışmasında öğrenci örneklemleri hariç cinsiyet farklılıklarının iş tecrübesinden etkilendiklerinin tespit etmişlerdir. Bu bağlamda iş tecrübesinin cinsiyet farklılığını arttırıcı etkisini ölçmek amacıyla düzenlenen araştırma hipotezi aşağıdaki gibidir:

\section{$H_{2 a}$ : Etik algısındaki cinsiyet farklılıkları çalışanın sektördeki tecrübesi arttıkça azalmaktadır.}

\section{$H_{2 b}$ : Etik algısındaki cinsiyet farklılıkları çalışanın şirketteki tecrübesi arttıkça azalmaktadır.}

Cinsiyet araştırmalarında göreceli bir karşılaştırma vardır. Çalışanların yönetici pozisyona sahip olup olmadığı, çalıştıkları sektör gibi farklılıklar bu karşılaştırmayı etkileyeceğinden analizlerde ele alınmıştır. Bu konudaki araştırmanın hipotezleri şu şekildedir:

$H_{3 a}:$ Etik algısındaki cinsiyet farklılıkları sektöre göre değişiklik göstermektedir. 
$H_{3 b}$ : Etik algıslndaki cinsiyet farklllıklarl yönetici olup olmama durumuna göre değişiklik göstermektedir.

Daha uzun süre iş hayatında olanlar ve iş güvenliğine sahip çalışanlar daha yüksek etik algısına sahiptirler (Ergenli ve Arıkan, 2002). Kamu sektöründen çıkarılma kriterlerinin azlığı göz önüne alındığında çalışanların özel sektöre oranla daha yüksek iş güvencesi olduğu şeklinde yorumlanabilir. Bu durumda iş güvencesi daha yüksek olan çalışanların olmayanlara göre daha etik davranma eğilimlerini öngören araştırma hipotezi şu şekildedir:

$H_{3 c}:$ Etik algısındaki cinsiyet farklılıkları çalışanın iş güvenliğine sahip olup olmama durumuna (kamu/özel) göre değişiklik göstermektedir.

\section{Etik Algısı ve Kuşaklar}

Kuşak (jenerasyon) teorisi (Generational Cohort Theory) insanların değerleri, tutum ve inançlarının değişimini toplumdaki sosyal değişimler, önemli tarihsel olaylar ile açıklamaktadır. Strauss ve Howe'nin (1991) Kuşaklar Amerika'nın Geleceği, 1584-2069” isimli kitabıyla popüler olmuştur. Onlara göre sosyal döngüler her dört kuşakta bir kendini tekrarlamaktadır. Kuşakların hangi yıllar arasında doğanları kapsadığı birçok kaynakta farklı görülebilmektedir. En kabul gören ve araştırmada kullanıldığı üzere kuşakların yaş aralıkları şu şekildedir (Weber ve Urick, 2017; Yıldız, 2016; Saruhan ve Yıldız, 2014; Zemke, Raines ve Filipczak, 2013; Costanza ve diğerleri, 2012):

- Büyük Kuşak: 1901 ile 1924 yılları arasında doğan,

- Sessiz Kuşak: 1925 ile 1945 yılları arasında doğan,

- Bebek Patlaması Kuşağı: 1946 ile 1960 yılları arasında doğan,

- X Kuşağı: 1961 ile 1980 yılları arasında doğan,

- Y Kuşağı: 1981 ile 2000 yılları arasında doğan ve

- Z Kuşağı: 2001 yılından günümüze kadar doğan çocukların oluşturduğu kuşaktır.

1946-1964 tarihleri arasında doğan bebek patlaması (baby boom, baby boomers) kuşağındakiler iş güvencesi taraftarıdırlar ve bir işletmede işe başlayıp emekli olana kadar orada devam etmeyi düşünürler. Çalışarak hayatlarını rahat yaşayacaklarını düşünürler ve çok çalıştıkça büyük ofisler, özel park yerleri gibi ödüller beklerler (Daft, 2007).

$X$ kuşağı (generation X, baby busters) ebeveynlerinin hatalarından nasıl kaçınacağını öğrendiler; eğitime, sıkı çalışmaya ve paranın gücüne değer veren bir kuşak olarak büyüdüler (Meier ve Crocker, 2010). Kariyerlerinin uzun soluklu olacağı ve çok çalışma gerektireceğini düşünürler. Ayrıca ebeveynleri kadar işkolik değillerdir ama iyi bir hayat yaşamak için çok çalışmaları gerektiğini bilirler. 
$Y$ kuşağl (generation Y, millennials, next generation, echo boomers) hedef odaklı, bağımsız, özgüvenlidir; genelde öğretmenleri ve ailelerinden çok daha fazla dijital dünyayı kullanıyorlar. Onlar için teknoloji herkese her yerde her zaman ulaşabilmeleri anlamına gelmektedir (Meier ve diğerleri 2010; Eisner, 2005; Martin, 2005). Bu kuşak, ebeveynleri X'ler tarafından çocukken çok korundular, çok az gözetimsiz bırakıldılar ve çatışmalarla çok nadiren karşılaştılar; çünkü ebeveynleri onların haklarını savundu (Howe ve Strauss, 2003). Ayrıca çocukken başarı için sıkı bir program ile motive edildiler, riskten kaçınmay1 ve firsatları kullanmayı ögrendiler (Vanmeter ve diğerleri, 2013). Hız çağında büyüyen Milenyumlar "her şeyi ve hemen istiyorlar". Başka deyişle; iyi bir ücret ve yan haklar, hızlı yükselme, iş-aile dengesi, ilginç, zorlayıcı bir iş ve topluma fayda sağlamayı istiyorlar $(\mathrm{Ng}$ ve diğerleri, 2010). Y kuşağı hayatlarının çok yönlülüğü içinde aynı anda birden fazla işi (okul, spor, sanat vb.) yaparak büyüdü. İnternette bir işi rahatlıkla aynı anda yapabilir. Hızlıca görevleri tamamlayıp bir sonrakine geçebilir ve iş hayatına girdiğinde sorumluluk almaya hazırdırlar. Durup yöneticilerinin onlara görev vermesini beklemezler (Meier ve Crocker, 2010). Kariyerini ön plana alan $X$ kuşağı yerine $Y$ kuşağı iş-aile dengesine önem vermektedir (Daft, 2007).

$Z$ kuşağl (generation Z, internet generation, generation @) henüz yeni yeni üniversitelere öğrenci olarak giriş yapmaktadır. Önceki kuşaklardan farklı özelliklere sahip olduğu tahmin edilmekle birlikte ancak birkaç yıl içerisinde $\mathrm{Z}$ kuşağı doğumlu örneklemler üzerinde çalışmalar görülebilecektir.

Kuşak araştırmalarına yapılan eleştirilerden biri her ülkenin kültürünün ve yaşadığı olayların birbirine göre farklılık gösterdiği ve bunun da aynı kuşakların birbirinden farklılaşmasına neden olduğudur. Bu özelliğiyle kuşak araştırmalarının kesinlik göstermeyen bir analiz alanıdır. Çünkü kuşakların ülkelerin yaşadığı sosyal, politik ve ekonomik olaylardan etkilenme derecesi farklılık göstermektedir. Örneğin, Almanya'da büyüyen bebek patlaması kuşağı 2 . Dünya Savaşı sonrası durgunluk dönemi etkileri taşırken Amerika aynı dönemde savaş sonrası başarıdan kaynaklanan bir iyimserlik ve gelişme içerisindeydi (Cogin, 2012). Murphy ve diğerleri (2004), kuşaklar arasında Amerika ve Japonya arasında hem benzerlik hem de farkl1lıklar tespit etmiştir. Bu nedenle bu araştırmaların farklı coğrafyalarda da yapılması önemlidir.

Etik karar verme ve iş tutumunda yaşın etkisi üzerine birçok araştırma yapılmıştır. Piaget'nin (1965) çocuk üzerindeki çalışmasını geliştiren Kohlberg (1969) ahlaki gelişimin 6 aşamalı modelini geliştirmiştir. Bu model üzerine Trevino (1986) örgütte bireylerin etik karar verme davranışlarını tahmin etmek için bireysel (ahlaki gelişim gibi) ve durumsal faktörleri ekleyerek yeni bir model (person situation interaction model) geliştirmiştir. Trevino'nun modeline göre, genç çalışanlar daha yaşlı çalışanlara göre genelde daha düşük ahlaki gelişim aşamasında olacaklarından etik sorunları çözmede dış faktörlere bakma eğilimindedirler. Kohlberg'in $(1981,1984)$ ahlaki gelişimi aşamalarına göre, bireyler üst aşa- 
malara geldikçe ahlaki çıkarımları artmaktadır. Gençlerin yaşlılardan daha düşük etik duyarlılığı olacağı öngörülmektedir. Ancak yaş ile etik karar verme arasındaki ilişkiye dair farklı sonuçlar bulunmaktadır Bazı çalışmalar (Lane, 1995; Thomas, 1985) yaş ile etik davranış arasında pozitif ilişki bulurken Cole ve Smith (1996) olgun insanların daha güçlü değerlere sahip olduğunu ifade etmektedir. Mitchell ve diğerlerine (1992) göre ise, genç çalışanlar yaşlı olanlara göre daha fazla etik bilince sahipler. Oldukça faklı sonuçlar elde edilmesine karşlık (Dalton ve Ortegren, 2011, Loe ve diğerleri, 2000; O'Fallon ve Butterfield, 2005) yaşa göre geliştirilen araştırma hipotezleri şu şekildedir:

\section{$H_{4}$ : Yaş ile etik davranışa tolerans gösterme arasında negatif iliş̧ki vardır.}

Ramsey ve diğerleri (2007) kuşakların, literatürün eşsiz tarihi olaylarının yarattığı kalıcı benzerlik ve farklılıkların kanıtları olduğunu öne sürmektedir. Ayrıca kuşak teorisi yaşa göre etik algı ve muhakemedeki farklılıkları daha iyi açıklama eğilimindedir. Bu bağlamda araştırmanın hipotezi şu şekildedir:

\section{$H_{5}: X, Y$ ve bebek patlaması kuşakları etik davranış algısı açısından farklılaşır.}

Kuşak çalışmalarına bakıldığında kullanılan en genel demografik faktörün cinsiyet olduğu görülmektedir. Parry ve Urwin (2011) "aynı kuşaktaki kadınların erkeklere göre farklı değerlere sahip olmasını beklemeli miyiz?" sorusunu sormuştur. Literatürde Terjersen ve diğerleri (2007), Eskilson ve Wiley (1999) kadınların erkeklere göre daha etik davranma eğiliminde olduklarını bulmuştur. Chen ve diğerleri (2016) 27 farklı ülkede yaptığı çalışmada erkeklerin rüşvet ve vergi kaçırma gibi işle ilgili etik dışı davranışları kadınlardan daha fazla gösterme eğiliminde olduğunu tespit etmiştir. Ahlaki karar verme kadınlarda daha yüksek (Herrington ve Weaven, 2008) ya da etik ikilemlerde kadınlar daha etik davranma eğilimindeler. Weber ve Urick (2017) Amerika'daki Y kuşağ yaptığı çalışmada kadın öğrencilerin erkek öğrencilerden etik değerlere daha fazla önem verdiğini tespit etmiştir. Buna göre aynı kuşaktaki kadın ve erkeklerin etik algısını ölçmeye yönelik geliştirilen hipotez şu şekildedir:

$\mathrm{H}_{6}: \mathrm{X}, \mathrm{Y}$ ve bebek patlaması kuşaklarındaki kadınlar aynı kuşaktaki erkeklerden daha fazla etik davranma eğilimindedirler.

\section{Yöntem}

Çalışmada hipotez test etmeye yönelik nicel araştırma yöntemi kullanılmıştır. Veri toplamada demografik 10 soru (doğum tarihi, cinsiyet vb.) ve etik algısının ölçümüne yönelik 10 soru olmak üzere toplam 20 sorudan oluşan anket kullanılmıştır. Anket verileri Ocak- Mayıs 2018 tarihleri arasında toplanmıştır. Anket sonuçlarından elde edilen verilerin analizinde istatistik programları kullanılmıştır. 


\section{Örneklem}

Zemke, Raines ve Filipczak (2013) tarafindan öne sürülen ve Costanza ve diğerleri (2012), Yildız (2016), Saruhan ve Yıldız (2014) tarafindan güncellenen ve uyarlanan doğum tarihleri kuşakların yaş aralıklarının belirlenmesinde kullanılmıştır. Türkiye'deki yaş oranlarına göre, Y kuşağından 460 çalışan (\%55,6), X kuşağından 256 çalışan (\%30,9) ve bebek patlaması kuşağından da $112(\% 13,5)$ çalışan orantılı örneklem yöntemiyle belirlenmiş ve anket yapılmıştır. Ayrıca kuşaklar içindeki cinsiyet oranları da göz önüne alınmıştır. Toplanan anketlerden eksik olanlar ve yanlış doldurulanlar çıkartılarak eksik sayılar tamamlandığında 828 anket analizlerde kullanılmıştır.

Araştırma örnekleminde çalışanların büyük çoğunluğu (\%78) lisans mezunuyken \%15'i lisansüstü ve $\% 7$ ise lise mezunudur. 313 kadın $(\% 37,8)$ ve 515 erkek $(\% 62,2)$ olan örneklemin \%20,7'si (171) sanayi sektöründe \%79,3’ü (657 çalışan) hizmet sektöründe çalışmaktadır. Kamu sermaye sahipliğinde çalışan sayısı $98(\% 11,8)$ ve özel sermaye sahipliğinde çalışan sayısı $730(\% 88,2)$ 'dur.

\section{Ölçekler}

Etik algısını ölçebilmek için Froelich ve Kottke (1991) ve Cole ve Smith (1995) tarafindan geliştirilen ve Cagle ve Baucus (2006) tarafindan adapte edilen 10 soruluk ölçek kullanılmıştır. "Çalışan işletmeyi korumak için müsşeriye yalan söyleyeme ihtiyacı duyabilir." ve "Çalışan işletmeyi korumak için başka bir çalışana yalan söyleyeme ihtiyacı duyabilir." ölçekteki sorulara örnektir. Araştırmada 1:Kesinlikle Katılmıyorum ve 6: Kesinlikle Katılıyorum'a kadar değişen ölçek kullanılmıştır. Ölçeğin Cronbach alpha kat sayısı 0,866'dır. Tek boyutlu olduğu için faktör analizi yapılmamıştır ancak kapsam geçerliliği için ölçek Türkçe ve İngilizce'ye çevrilmiş ve 3 akademisyen ve 40 çalışan ile yüz yüze anket formları doldurtulmuş, ankette anlaşılmayan ifadeler düzeltilmiştir.

Ayrıca etik davranışlara dair insanların hassasiyetleri düşünülerek doğru cevaplamayı sağlamak amacıyla anketler çalışanlara kapalı zarf içerisinde verilmiş ve cevaplandıktan sonra aynı şekilde toplanmıştır.

\section{Bulgular}

Araştırmaya katılanların etik-dışı davranışlara verdikleri cevapların ortalama ve standart sapma değerleri Tablo 1'de görüldüğü gibidir: 
Tablo 1

Çalışanların Etik Algılarının Ortalama ve Standart Sapma Değerleri

\begin{tabular}{|c|c|c|c|}
\hline & $\mathbf{N}$ & ORT. & SD \\
\hline $\begin{array}{l}\text { Yönetici bir çalışana başka bir çalışanın yanlış bakış açısını desteklemes- } \\
\text { ini isteyebilir. }\end{array}$ & 1200 & 1,9 & 1,447 \\
\hline İşletmede bazen rekabetin gerektirdiği şaibeli uygulamalar gerekebilir. & 1200 & 1,96 & 1,428 \\
\hline $\begin{array}{l}\text { Çalışanlar eğer işletmenin çıkarınaysa başka bir çalışanın yanlış } \\
\text { davranışını görmezden gelebilir. }\end{array}$ & 1200 & 2,09 & 1,520 \\
\hline $\begin{array}{l}\text { Yöneticiler istenilen sonuca ulaşıldıysa, amacın nasıl gerçekleştirildiğini } \\
\text { umursamamalıdır. }\end{array}$ & 1200 & 1,91 & 1,384 \\
\hline $\begin{array}{l}\text { Yöneticinin çalışanından bir doküman üzerindeki sayılarda biraz dü- } \\
\text { zeltme istemesinde bir sorun yoktur. }\end{array}$ & 1200 & 2,11 & 1,514 \\
\hline Karlılık ürün kalitesinden (güvenilirliğinden) daha önceliklidir. & 1200 & 1,88 & 1,374 \\
\hline $\begin{array}{l}\text { Çalışan işletmeyi korumak için müşteriye yalan söyleyeme ihtiyacı } \\
\text { duyabilir. }\end{array}$ & 1200 & 2,33 & 1,609 \\
\hline $\begin{array}{l}\text { Çalışan işletmeyi korumak için başka bir çalışana yalan söyleyeme } \\
\text { ihtiyacı duyabilir. }\end{array}$ & 1200 & 2,00 & 1,435 \\
\hline $\begin{array}{l}\text { Çalışan işletmeyi korumak için yöneticisine yalan söyleyeme ihtiyacı } \\
\text { duyabilir. }\end{array}$ & 1200 & 1,92 & 1,388 \\
\hline $\begin{array}{l}\text { Çalışan işletmeyi korumak için rakip firma çalışanına yalan söyleyeme } \\
\text { ihtiyacı duyabilir. }\end{array}$ & 1200 & 3,15 & 1,829 \\
\hline Toplam & 1200 & 2,12 & 1,000 \\
\hline
\end{tabular}

$\mathrm{H}_{1}$ hipotezi olan kadın erkek arasındaki farklılığı test etmek için yapılan ki-kare bağımsızlık analizi sonuçları şu şekildedir:

Tablo 2

Cinsiyete Göre Etik Algısı Ki-Kare Sonuçları

\begin{tabular}{lcccc}
\hline & & \multicolumn{2}{c}{ Etik Algısı } & \multirow{2}{*}{ Toplam } \\
\cline { 3 - 4 } & & Orta altı ahlak & Orta üstü ahlak & 313 \\
Cinsiyet & Kadın & 124 & 189 & 515 \\
Toplam & Erkek & 245 & 270 & 828 \\
\hline
\end{tabular}

Tabloda görüldüğü gibi Ki-Kare Bağımsızlık Testi uygulaması sonucunda Sig. değeri 0,05’ten küçük elde edilmiştir. Dolayısı ile etik algısı ile cinsiyet arasında ilişki olduğu (etik algısının cinsiyetten bağımsız olmadığı) söylenebilir. Kadın erkeklerin etik algısı ortalamalarına bakıldığında kadınların etik algılarının $(2,072)$ ve erkeklerinkinden $(3,147)$ daha yüksek olduğu söylenebilir. 6'lı ölçek kullanıldığından erkeklerin anlamlı şekilde daha fazla etik dışı davranışlarını kabul etme eğiliminde olduğu görülmektedir. $\mathrm{H}_{1}$ hipotezi kabul edilir. 
Örneklemin genelinde sektördeki tecrübe arttıkça (r:-0,068, Sig.0,019) ve şirkette çalışma yılı arttıkça (r:-0,072, Sig.0,012) etik-dışı davranışa tolerans gösterme düzeyi azalmaktadır. Sektörde çalışma yılı 10 yıl ve daha az olan (tecrübesi az çalışan - \%49,6) ve 10 yıldan fazla (tecrübeli çalışan - 50,4) tecrübesi olan çalışanlardan iki grup oluşturularak analize tabii tutulmuştur. Sektörde tecrübe arttıkça çalışanların etik dışı davranışlara yönelme eğilimi artmaktadır (r: -0,68, Sig. 0,0019). Aynı şekilde şirkette çalışma yılına bakıldı̆̆ında negatif yönlü düşük düzeyde ilişki bulunmuştur (r: $-0,25$, Sig. 0,00 ). Ancak cinsiyete göre etik algısını etkileyen anlamlı bir farklılık bulunmamıştır. $\mathrm{H}_{2 \mathrm{a}}$ hipotezi reddedilir.

Şirkette 10 yıldan az tecrübesi olan kadınlar (ort.1,8694) ile erkekler (ort.1,9286) arasında anlamlı bir etik algısı farklılık bulunamamıştır. Ancak 10 yıldan fazla süredir şirkette çalışanlar için kadın ve erkeklerin etik algıları birbirinden istatistiki olarak farklıdır (F: 0,743, Sig. 0,389, t: -2,515, Sig. 0,012). Etik algı ortalamalarına bakıldığında iş tecrübesi yüksek olan kadınların (10 yıldan fazla) etik-dışı davranış tolerans ortalaması 1,7417 iken erkekler 2,0835 olduğu görülmüştür. $\mathrm{H}_{2 \mathrm{~b}}$ hipotezi kabul edilir.

Hizmet sektörü çalışanları sanayi sektörü çalışanlardan istatistiki olarak anlamlı düzeyde daha etik davranmaya eğilimlidirler (t: 2,320, df: 1198, Sig.=0,021). Sanayi ve hizmet sektöründe çalışanların etik dışı davranış algısından cinsiyet farklılığına etkisi olup olmadığını test etmek için yapılan bağımsız gruplarda t-testi sonuçları anlamlı çıkmamışır. $\mathrm{H}_{3 \mathrm{a}}$ hipotezi reddedilir.

$\mathrm{H}_{3 \mathrm{~b}}$ hipotezinde yönetici olma-olmama durumuna göre etik algısındaki farklılıklar bağımsız gruplarda t testi ile test edilmiş̧ir. Analiz sonuçlarına göre kadın yöneticiler ile (ort: 1,85) erkek yöneticiler için (ort: 3,18) anlamlı düzeyde farklılık (t: -2,161, df: 216, Sig.=0,032) vardır. Yönetici kadınlar yönetici erkeklerden daha etik davranma eğilimindedir. Yönetici olmayan kadın ile erkek çalışanlar arasındaki fark ise anlamlı değildir.

Tüm örneklemde etik algısının iş güvencesi farklılıklarına bakıldığında kamu sektörü çalışanların özel sektör çalışanlardan daha yüksek etik algısına sahip olduğu görülmektedir (t: 2,038, df:826 Sig.0,042). İş güvenliği olan çalışanlar etik dış1 davranışa daha az tolerans göstermektedir. Ancak iş güvencesinin varlığı-yokluğu cinsiyete göre farklılaşmamaktadır. $\mathrm{H}_{3 \mathrm{c}}$ hipotezi reddedilir.

Yaş ile etik algısı ilişkisini öneren $\mathrm{H}_{4}$ aralarında anlamlı ilişki bulunmadığı için reddedilmiştir. " $H_{5}: X, Y$ ve bebek patlaması kuşakları etik davranış algısı açısından farklılaşır." hipotezini test etmek için yapılan ANOVA testi sonuçlarına göre $X$ ve $Y$ kuşağı birbirinden etik algısı açısından farklılaşmaktadır. Tablo 3'de kuşakların cinsiyete göre etik dışı davranış tolerans ortalamaları ve standart sapmaları özetlenmektedir. Kuşaklara göre etik algısının ortalama grafiği de aşağıdaki şekilde görülmektedir. 


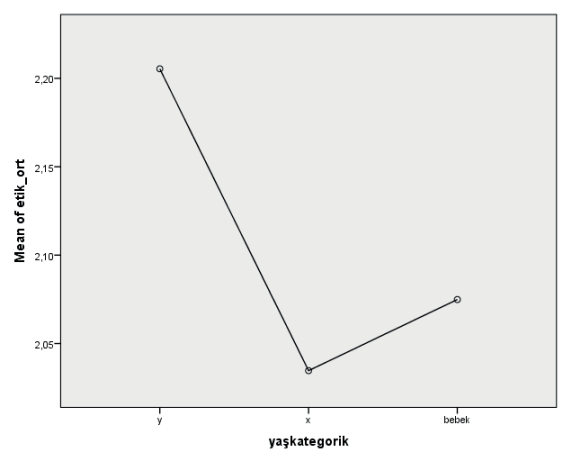

Şekil 1. Kuşaklara göre etik algısı ortalama grafiği

Bebek patlaması ile X ve Y kuşakları arasında anlamlı farklılık bulunmamıştır. Y kuşağ1 ise $\mathrm{X}$ ve bebek patlaması kuşaklarından anlamlı düzeyde daha yüksek düzeyde etik dışı davranışları benimseme eğilimindedir. Ancak ortalama grafiğine baktığımızda x kuşağının etik dışı davranışa en az toleransı gösterdiği görülmektedir.

$\mathrm{H}_{6}$ test etmek yapılan analiz sonuçlarına göre, Tablo 3'de detaylı olarak görüldüğü üzere, sorulara verilen cevaplarda aynı kuşağa ait kadınların aynı kuşak mensubu erkeklere göre istatistiki anlamlı olarak daha etik davranma eğilimde olduğu görülmektedir. Ancak Y kuşağı çalışanların etik algılarında kadın ve erkekler arasında istatistiki olarak anlamlı farklılık bulunmamıştır.

Özetle, Tablo 4'de araştırmanın hipotezleri ve yukarıda özetlenen sonuçları görülmektedir. Araştırmada $\mathrm{H}_{1}, \mathrm{H}_{2 \mathrm{a}}, \mathrm{H}_{2} \mathrm{~b}, \mathrm{H}_{3 \mathrm{a}}, \mathrm{H}_{3 \mathrm{c}}$ ve $\mathrm{H}_{4}$ kabul edilirken $\mathrm{H}_{3 \mathrm{~b}}, \mathrm{H}_{5}$ ve $\mathrm{H}_{6}$ kısmen kabul edilmiştir.

Tablo 3

İşyerinde Etik Algısının Kuşaklara ve Cinsiyete Göre Ortalama ve Standart Sapma Sonuçları

\begin{tabular}{|c|c|c|c|c|c|c|c|c|c|c|c|c|}
\hline & \multicolumn{4}{|c|}{ Bebek Patlaması } & \multicolumn{4}{|c|}{ X Kuşağı } & \multicolumn{4}{|c|}{ Y Kuşağı } \\
\hline & \multicolumn{2}{|c|}{ Kadın } & \multicolumn{2}{|c|}{ Erkek } & \multicolumn{2}{|c|}{ Kadın } & \multicolumn{2}{|c|}{ Erkek } & \multicolumn{2}{|c|}{ Kadın } & \multicolumn{2}{|c|}{ Erkek } \\
\hline & Ort & $\begin{array}{c}\text { St. } \\
\text { Sapma }\end{array}$ & Ort & $\begin{array}{c}\text { St. } \\
\text { Sapma }\end{array}$ & Ort & $\begin{array}{c}\text { St. } \\
\text { Sapma }\end{array}$ & Ort & $\begin{array}{c}\text { St. } \\
\text { Sapma }\end{array}$ & Ort & $\begin{array}{c}\text { St. } \\
\text { Sapma }\end{array}$ & Ort & $\begin{array}{c}\text { St. } \\
\text { Sapma }\end{array}$ \\
\hline Etik alg1 S1 & 1,64 & 1,348 & 1,86 & 1,237 & 1,61 & $1,231 *$ & 2,02 & 1,461 & 1,86 & 1,86 & 1,93 & 1,500 \\
\hline Etik alg1 S2 & 1,63 & 1,159 & 2,24 & 1,210 & 1,87 & 1,413 & 1,76 & 1,239 & 2,24 & 2,24 & 2,01 & 1,475 \\
\hline Etik alg1 S3 & 1,43 & $1,194^{*}$ & 2,09 & 1,343 & 1,83 & 1,414 & 2,09 & 1,424 & 2,09 & 2,09 & 2,30 & 1,583 \\
\hline Etik alg $1 \mathrm{~S} 4$ & 1,47 & 1,074 & 1,94 & 1,032 & 1,50 & $1,113^{*}$ & 1,97 & 1,379 & 1,94 & 1,94 & 2,07 & 1,501 \\
\hline Etik alg1 S5 & 1,77 & 1,104 & 2,19 & 1,239 & 1,66 & 1,273 & 1,98 & 1,396 & 2,19 & 2,19 & 2,39 & 1,674 \\
\hline Etik alg1 S6 & 1,33 & $0,758^{*}$ & 1,91 & 1,216 & 1,57 & $1,071 *$ & 1,90 & 1,380 & 1,91 & 1,91 & 1,97 & 1,446 \\
\hline Etik alg1 S7 & 2,07 & 1,680 & 2,49 & 1,455 & 2,00 & 1,551 & 2,13 & 1,468 & 2,49 & 2,49 & 2,40 & 1,656 \\
\hline Etik alg1 S8 & 1,77 & 1,357 & 1,91 & 1,257 & 2,10 & 1,616 & 1,94 & 1,87 & 1,91 & 1,91 & 2,09 & 1,513 \\
\hline Etik alg1 S9 & 1,33 & $0,758 *$ & 1,98 & 1,288 & 1,54 & $1,017^{*}$ & 1,89 & 1,258 & 1,98 & 1,98 & 2,04 & 1,465 \\
\hline Etik alg 1 S10 & 3,77 & 2,012 & 3,02 & 1,580 & 2,51 & $1,767^{*}$ & 3,16 & 1,825 & 3,02 & 3,02 & 3,21 & 1,867 \\
\hline $\begin{array}{l}\text { Etik algısı } \\
\text { ortalama }\end{array}$ & 1,82 & 0,620 & 2,109 & 0,784 & 1,82 & 0,946 & 2,08 & 0,973 & 2,16 & 1,180 & 2,241 & 1,047 \\
\hline
\end{tabular}


Tablo 4

Araştırma Hipotezleri ve Analiz Sonuçları

\begin{tabular}{|c|c|}
\hline Hipotezler & Sonuç \\
\hline H1: İşyerindeki etik algısı cinsiyete göre farklılaşır. & KABUL \\
\hline $\begin{array}{l}\text { H2a: Etik algısındaki cinsiyet farklılıkları çalışanın sektördeki tecrübesi arttıkça } \\
\text { azalmaktadır. }\end{array}$ & RED \\
\hline $\begin{array}{l}\text { H2b: Etik algısındaki cinsiyet farklılıkları çalışanın şirketteki tecrübesi arttıkça } \\
\text { azalmaktadır. }\end{array}$ & KABUL \\
\hline H3a: Etik algısındaki cinsiyet farklılıkları sektöre göre değişiklik göstermektedir. & RED \\
\hline $\begin{array}{l}\text { H3b: Etik algısındaki cinsiyet farklılıkları yönetici olup olmama durumuna göre değişiklik } \\
\text { göstermektedir }\end{array}$ & KISMEN KABUL \\
\hline $\begin{array}{l}\text { H3c: Etik algısındaki cinsiyet farklılıkları çalışanın iş güvenliğine sahip olup olmama duru- } \\
\text { muna (kamu/özel) göre değişiklik göstermektedir. }\end{array}$ & RED \\
\hline H4: Yaş ile etik davranışa tolerans gösterme arasında negatif ilişki vardır. & RED \\
\hline H5: X, Y ve bebek patlaması kuşakları etik davranış algısı açısından farklılaşır. & KISMEN KABUL \\
\hline $\begin{array}{l}\text { H6: X, Y ve bebek patlaması kuşaklarındaki kadınlar aynı kuşaktaki erkeklerden daha fazla } \\
\text { etik davranma eğilimindedirler. }\end{array}$ & KISMEN KABUL \\
\hline
\end{tabular}

\section{Sonuçlar ve Tartışma}

Araştırma Türkiye'de sanayi ve hizmet sektöründe Y kuşağından 460 çalışan $(\% 55,6)$, X kuşağından 256 çalışan $(\% 30,9)$ ve bebek patlaması kuşağından da $112(\% 13,5)$ çalışan olmak üzere toplam 828 anket analize katılmışıtır. Araştırmanın amacı kuşak ve cinsiyet farklılıklarının işyerinde etik algısında yarattığı değişimlerdir. Sosyal rol ve sosyalizasyon teorileri bağlamında cinsiyetin işyerinde etik algısında yarattı̆̆ farklar değerlendirilmeye çalışılmıştır.

Türkiye'de cinsiyetin etik algıları ve karar verme süreçlerinde yarattığı farklılık satış personelleri (Ergeneli ve Arıkan, 2002; Ekin ve Tezölmez, 1999), öğrenciler (Atakan, Burnaz ve Topçu, 2008) ve yöneticiler üzerinde test edilmiştir (Askun ve diğerleri, 2010). Atakan, Burnaz ve Topçu (2008) Türkiye örnekleminde yaptıkları çalışmalarında kadın öğrencilerin erkekler öğrencilere göre daha etik davrandıklarını tespit etmişlerdir. Ekin ve Tezölmez (1999) çalışan örneklemi ile yaptığı araştırmalarında kadın yöneticilerin etik muhakemeleri erkek yöneticilere göre daha yüksek olmakla birlikte bireysel, yönetsel ve örgütsel faktörlerin etik muhakemede istatistiki anlamlı bir farklılık görülmemiştir. Ergeneli ve Arıkan (2002) Türkiye'deki çalışanlar üzerine yaptığı araştırmaya benzer şekilde kadınların erkeklerden daha etik davrandığ 1 tespit edilmiştir. 1200 çalışan üzerinde yapılan bu araştırmada kadınlar erkeklerden daha etik olduğu sonucuna ulaşılmış ve $\mathrm{H}_{1}$ hipotezi kabul edilmişsir.

Literatürde öngörülen iş tecrübesinin etik algısındaki cinsiyet farklılıklarını azaltacağ görüşü sektördeki ve şirketteki iş tecrübesi olarak $H_{2 a}$ ve $H_{2 b}$ hipotezlerinde ele alınmış ve 
kabul edilmiştir. Çalışanlar daha uzun süre çalıştıkça kadın ile erkek arasındaki etik-dışı davranış tolerans farklılığ azalmaktadır. İş tecrübesi hem sektörde hem de şu anki işyerindeki tecrübesine bakılarak değerlendirilmiştir.

Franke, Crown ve Spake (1997) ve Türkiye örnekleminde Ergenli ve Arıkan (2002) aksine Eweje ve Brunton (2010) çalışmalarına benzer şekilde araştırma sonuçlarına göre etik algısındaki cinsiyet farklılıkları sektöre ve iş güvencesine göre değişiklik göstermemektedir.

Türkiye İstatistik Kurumu tarafından yayınlanan "İstatistiklerle Kadın, 2017” raporuna göre Türkiye'de kadın yönetici oranı \%16,'dır. Araştırma örneklemindeki kadın yöneticilerin oranına benzer bir oran söz konusudur. Yönetici olup olmamanın cinsiyet farklılığına etkisine bakıldığında yönetici kadınlar yönetici erkeklerden daha etik davranma eğilimdedir. Sektörde 10 yıldan fazla çalışan kadın (ortalama: 1,70$)$ ve erkek $(2,16)$ yöneticiler karşılaştırıldığında istatistiki olarak anlamlı şekilde kadınların işyerinde etik-dışı davranışa toleransı erkeklerden daha düşüktür (t: -2,088, df. 162, Sig.0,023). 10 yıldan az tecrübeli yöneticileri kiyaslarken çalışan sayısının azlığı $(\mathrm{N}=54)$ göz önüne alındığında analizin anlamlı çıkmaması beklenen bir sonuçtur.

Genç çalışanlar yaşlı çalışanlara göreceli olarak daha fazla etik dışı davranışları kabul etme eğilimdedirler (Dalton ve Ortegren, 2011). Çoğu çalışma yaş ile etik davranış arasında bir ilişki bulamamasına rağmen cinsiyet farklılıkları yazında önemli bir değişken olarak karşımıza çıkmaktadır. Araştırma sonuçlarına göre literatürde birçok çalışma sonuçlarına (Eweje ve Brunton, 2010; Honeycutt ve diğerleri, 2001; Brady ve Wheeler, 1996; Callan, 1992) benzer şekilde farklılık tespit edememiştir. Türkiye örnekleminde kadınlar erkeklerden ve yönetici kadınlar da yönetici erkeklerden daha yüksek etik algısına sahipler.

Kuşaklar arası farklılığına geldiğimizde ise Posthoc Tamhane sonuçlarına göre, etik algıları açısından Y kuşağı ile X kuşağı arasında anlamlı düzeyde farklılık tespit edilmişstir. Araştırma sonuçları, literatürden farklı şekilde Türkiye'deki Y kuşağının X ve bebek patlaması kuşaklarından daha fazla etik dışı davranma eğiliminde olduğunu göstermektedir. Etik liderlik, etik değerler ve kodlar tüm Dünya gündemindeyken literatürde farklı örneklemlerdeki çalışmalar Y kuşağını etik kodları ve beklentilerinin yüksek olduğu (Curtin ve diğerleri, 2001) ve etik kodu yüksek hizmetkâr liderlik özelliklerine yatkın oldukları ve etik dışı davranmamaya çaba gösterecekleri (Vanmeter ve diğerleri, 2013) sonuçlarına ulaşmışken hatta sosyal konulara daha fazla bilince ve farkındalığa sahip olmalarına rağmen Türkiye'de Y kuşağı kendisinden önceki kuşaklardan daha az etik davranmaya meyillidir. Y kuşağının bu algısı Türkiye'de yaşadığı ve gördüğü olaylarla ilişkilendirilebilir. Bu bağlamda teknolojik gelişmelerin birbirine benzettiği dijital dünyada dahi kuşak çalışmalarının toplumdan topluma ne kadar değiştiğinin ve göreceli olduğunun önemli bir göstergesidir. 
Araştırma sonuçları; literatürde küresel düzeyde sorumlu liderlik (Williams ve Turnbull, 2015) ve hizmetkâr liderlik özellikleri taşıyan çalışanlar (Vanmeter ve diğerleri, 2013) olarak tanımlanan Y kuşağının Türkiye'deki üyelerinin kendisinden önceki kuşaklara göre daha fazla etik dışı davranışta bulunmaya ve bunları kabul etmeye meyilli olduğunu göstermektedir.

Geleceğin işletme liderlerinin işyerinde etik dışı davranış potansiyeli oldukça dikkat edilmesi gereken bir konudur (Hanna ve diğerleri, 2013). Örgütler için etik eğitimler ilk öneri olabilmekle birlikte Milenyumların etik muhakemelerini şekillendirmek için etik konularda rol model yaratması da oldukça etkili kendiliğinde kültürlenme yöntemlerinden biri olacaktır.

Mentorlar ya da süpervizörler Milenyum kuşağının işyerlerinde etik değerler ve prensipler kazanmasında yardımcı olabilir (Culiberg ve Mihelic, 2016). Etik liderler benzer şekilde rol model olma ve davranış kodlarını şekillendirme konusunda oldukça etkili olabilirler. Örgütler yeni kuşakların etik dışı davranış eğilimlerini iyi değerlendirmeli ve şekillendirmelidir.

Her araştırmada olduğu gibi bu araştırmanın da bir takım sınırlılıkları söz konusudur. Öncelikli olarak veri toplama sürecinde tabakalı örnekleme yöntemi kullanıldıysa da gönüllü çalışanlar ankete cevap vermişlerdir. Örneklem büyük ve ana kütleyi temsil gücü yüksek olsa da yeterli olmayabilir. Araştırmada etik dışı davranış toleransını ölçmek için anket yöntemi kullanılmıştır. Anketin geçerlilik güvenilirlik değerleri yüksek olmasına rağmen veri toplama yönteminden kaynaklanan bazı kısıtlılıklar söz konusudur. Çalışanlara zarf içerisinde ve kapalı şekilde dağıtılmış olmasına rağmen etik araştırmaları hassas bir veri toplama süreci gerektirir. Öte yandan etik algısı, etik muhakeme ve karar verme ile ilgili analizlerde genelde örnek olaylar ve senaryolar kullanılmaktadır. Araştırmada kullanılan veri toplama yöntemi diğer yöntem olan senaryolardan daha nicel bir analize izin verdiği için göreceli olarak daha avantajlı olarak değerlendirilebilir.

Araştırmanın en temel katkısı etik-dışı davranışa tolerans gösterme düzeyini Türkiye'de 828 çalışandan oluşan geniş bir örneklemde incelemesidir. Ayrıca araştırma örneklemin çalışanlardan oluşması benzer konulu birçok araştırmanın öğrenciler üzerinde yapılması nedeniyle yazına farklı düzeyde yeni bilgi sağlamaktadır. Weber ve Urick’in $(2017,2018)$ güncel çalışmalarında da görüldüğü üzere, Amerika öğrencilerinden oluşan Y kuşağı daha etik davranma eğilimde iken Türkiye'deki Y kuşağının etik algısı farklılık göstermektedir. Bu nedenle kuşak çalışmalarının işletmelerin kendi kültürlerinde büyük örneklemlerle yapılması önemlidir.

Yönetici kadınlar daha etik davranırken yönetici olan ve olmayan tüm çalışanlar örnekleminde de kadınlar daha etik davranmaktadır. Türkiye' deki yönetici kadınlar üzerinde etik algısını ölçen bir çalışma bulunmamaktadır. Araştırma Türkiye'de çalışanları hem cinsiyet hem de kuşak karşılaştırması yapan nadir çalışmalardan biridir. Bu özelliğiyle de hem ulusal hem de uluslararası yazına güncel bilgi sağlama özelliğine sahiptir. 
Türkiye'deki giderek daha fazla yönetici konumuna gelen Y kuşağının kendisinden önceki kuşak çalışanlarına göreceli olarak etik dışı davranma eğilimleri işletmeler için riskli olarak değerlendirilmelidir. Etik dışı davranma eğilimi beraberinde şirket içinde duygusal taciz, cam tavan vb. birçok olumsuz sonuç yaratabilir.

İşletmeler Y kuşağının bu eğilimi yönlendirebilmek için etik rol model yöneticiler istihdam ettirmeli, kamuoyuna ve çalışanlara etik kodlarını açıklamalı, yönetim süreçlerinde tutarlı ve adil olmalıdır. Ayrıca etik konularında eğitimler verilebilir. Yöneticilerin eşit ve etik davranışları işletmedeki etkileşimsel adalet algısını arttıırıen, özellikle insan kaynakları süreçlerinin şeffaf olması dağıtımsal ve işlemsel adalet algısını arttırabilmektedir.

Finansal Destek: Bu araştırma Marmara Üniversitesi Bilimsel Araştırma Projeleri Birimi tarafından SOS-B-070617-0394 proje numarasıyla desteklenmiştir.

\section{Kaynakça/References}

Atakan, M. G. S., Burnaz, S., \& Topcu, Y. İ. (2008). An empirical investigation of the ethical perceptions of future managers with a special emphasis on gender - Turkish case. Journal of Business Ethics, 82(3), $573-586$.

Cogin, J. (2012). Are generational differences in work values fact or fiction? Multi-country evidence and implications. The International Journal of Human Resource Management, 23(11), 2268-2294.

Cole, B. C., \& Smith, D. L. (1996). Perceptions of business ethics: Students vs. Business People. Journal of Business Ethics, 15(8), 889-896.

Costanza, D. P., Badger, J. M., Fraser, R. L., Severt, J. B., \& Gade, P. A. (2012). Generational Differences in Work-Related Attitudes: A Meta-analysis. Journal of Business and Psychology, 27(4), 375-394.

Costanza, D. P., \& Finkelstein, L. M. (2015). Generationally Based Differences in the Workplace: Is There a There There? Industrial and Organizational Psychology, 8, 308-323.

Craft, J. L. (2018). Common Thread: The Impact of Mission on Ethical Business Culture. A Case Study. Journal of Business Ethics, 149, 127-145.

Culiberg, B., \& Mihelič, K. K. (2015). Three ethical frames of reference: Insights into Millennials' ethical judgements and intentions in the workplace. Business Ethics: A European Review, 25(1), 94-111.

Curtin, P. A., Gallicano, T., \& Matthews, K. (2011). Millennials' Approaches to Ethical Decision Making: A Survey of Young Public Relations Agency Employees. Public Relations Journal, 5(2), 1-22.

Daft, R. (2007). The new era of management. Thomson Learning Pub.

Dalton, D., \& Ortegren, M. (2011). Gender Differences in Ethics Research: The Importance of Controlling for the Social Desirability Response Bias. Journal of Business Ethics, 103, 73-93.

Eagly, A. H., \& Wood, W. (2016). Social Role Theory of Sex Differences; N. Naples, R. C. Hoogland, M. Wickramasinghe, \& W.C.A. Wong (Eds.) kitabı içinde bölüm.

Eagly, A. H. (2005). Achieving relational authenticity in leadership: Does gender matter? The Leadership Quarterly, 16, 459-474. 
Eddy S. W. Ng, E.S.W., Schweitzer, L., \& Lyons, S. T. (2010). New generation, great expectations: A field study of the millennial generation. Journal of Business and Psychology, 25, 281-292.

Ekin, M. G. S., \& Tezölmez, S. H. (1999). Business ethics in Turkey: An empirical nnvestigation with special emphasis on gender. Journal of Business Ethics 18(1), 17-34.

Ergeneli, A., \& Arikan, S. (2002). Gender differences in ethical perceptions of salespeople: An empirical examination in Turkey. Journal of Business Ethics, 40(3), 247-260.

Franke, G. R., Crown, D. E., \& Spake, D. E. (1997). Gender differences in ethical perceptions of business practices: A social role theory perspective. Journal of Applied Psychology, 82(6), 920-934.

Gilligan, C. (1982). In a different voice. Cambridge: Harvard University Press.

Glover, S. H., Bumpus, M. A., Sharp, G. F., \& Munchus, G. A. (2002). Gender differences in ethical decision making. Women in Management Review, 17(5), 217-227.

Greenwood, M. (2013). Ethical analyses of HRM: A review and research agenda. Journal of Business Ethics, 114(2), 355-366.

Hanna, R. C., Crittenden, V. L., Crittenden, W. F. (2013). Social learning theory: A multicultural study of influences on ethical behavior. Journal of Marketing Education, 35(1), 18-25.

Harris, J. R. (1990). Ethical values of individuals at different levels in the organizational hierarchy of a single firm. Journal of Business Ethics, 9, 741-750.

Hauw S. De, A. De Vos (2010). Millennials' Career Per- spective and Psychological Contract Expectations: Does the Recession Lead to Lowered Expectations? Journal of Business and Psychology, 25(2), 293- 302.

Ho, J. A. (2010). Ethical perception: are differences between ethnic groups situation dependent? Business Ethics: A European Review, 19(2), 154-182.

Honeycutt, Jr., E. D., Glassman, M., Zugelder, M. T., \& Karande, K. (2001). Determinants of ethical behavior: A study of autosalespeople. Journal of Business Ethics, 32, 69-79.

Loe, T. W., Ferrell, L., \& Mansfield, P. (2000). A review of empirical studies assessing ethical decision making in Business. Journal of Business Ethics, 25, 185-204.

Lund, D. L. (2008). Gender differences in ethics judgment of marketing professionals in the United States. Journal of Business Ethics, 77, 501-515.

Mayer, D. M. Kuenzi, M., \& Greenbaum, R. L. (2010). Examining the link between ethical leadership and employee Misconduct: The mediating role of ethical climate. Journal of Business Ethics, 95, 95:7-16.

Meier, J., \& Crocker, M. (2010). Generation Y in the workforce: Managerial challenges. The Journal of Human Resource and Adult Learning, 6(1), 68-78.

Murphy, E. F., Gordon, J. D., \& Anderson, T. L. (2004). Cross-Cultural generational differences between the United States and Japan. Journal of Applied Management and Entrepreneurship, 9, 21-48.

O'Fallon, M. J., Butterfield, K. D. (2005). A review of the empirical ethical decision-making literature: 19962003. Journal of Business Ethics, 59(4), 375-413.

Parry, E., \& Peter Urwin, P. (2011). Generational differences in work values: A Review of theory and evidence. International Journal of Management Review, 13(1), 19-96.

Peterson, D., Rhoads, A., \& Vaught, B. C. (2001). Ethical beliefs of business professionals: A study of gender, age and external factors. Journal of Business Ethics, 31(3), 225-232.

Ramsey, R. P., Marshall, G. W., Johnston, M. W., \& Deeter-Schmelz, D. R. (2007). Ethical 1deologies and older consumer perceptions of unethical sales tactics. Journal of Business Ethics, 70(2), 191-207. 
Roxas, M. L., \& Stoneback, J. Y. (2004). The importance of gender across cultures in ethical decision-making. Journal of Business Ethics, 50(2), 149-165.

Saruhan, S. C., \& Yıldız, M. L. (2014). İnsan kaynakları yönetimi: Teori ve uygulama. İstanbul: Beta Yayınları.

Terjesen, S., Vinnicombe, S., \& Freeman, C. (2007). Attracting generation Y graduates: Organizational attributes, likelihood to apply and sex differences. Career Development International, 12, 504-522.

Thomas, T., Schermerhorn, J.R., \& Dienhart, J. W. (2004). Strategic leadership of ethical behavior in Business. Academy of Management Executive, 18(2), 56-66.

Trevino, L. K. (1986). Ethical decision making in organizations: A person-situation interactionist model. The Academy of Management Review, 11(3), 601-617.

Vos, A. De, K. De S., \& Meganck, A. (2009). The relationship between career-related antecedents and graduates' anticipatory psychological contracts. Journal of Business and Psychology, 24(3), 289-298.

Weber, J., Urick, M. J. (2017). Examining the millennials' ethical profile: Assessing demographic variations in their personal value orientations. Business and Society Review 122(4), 469-506.

Weeks, W. A., Moore, C. W., McKinney, J.a., Longenecker, J. G. (1999). The effects of gender and career stage on ethical judgment. Journal of Business Ethics, 20(4), 301-313.

Whitley, Jr., B. E., Nelson, A. B., \& Jones, C. J. (1999). Gender differences in cheating attitudes and classroom cheating behavior: A meta-analysis. Sex Roles, 41, 657-680.

Wittmer, D. P. (2000). Ethical sensitivity in management decisions: Developing and testing a perceptual measure among management and professional student groups'. Teaching Business Ethics, 4(2), 181-205.

Yıldız, M. L. (2016). Managing generation Y: A study of generational shifts in Turkey, ABSRC Milan 2016, Milan: Italy, October 20-21.

Yıldız, M. L. (2016a). Generational Differences in Perceptions of Leadership, 2016 International Academic Business Conference, Venice: Italy, June 6-8. (Best Paper Award)

Zabel, K. L., Biermeier-Hanson, B. B. J., Baltes, B. B., Early, B. J., \& Shepard, A. (2017). Generational differences in work ethic: Fact or fiction? Journal of Business and Psychology, 32(3), 301-315.

Zemke, R., Raines, C., \& Filipczak, B. (2013). Generations at work: Managing the Clash of Veterans, Boomers, Xers, and Nexters in Your Workplace, Second Edition, Amacom. 